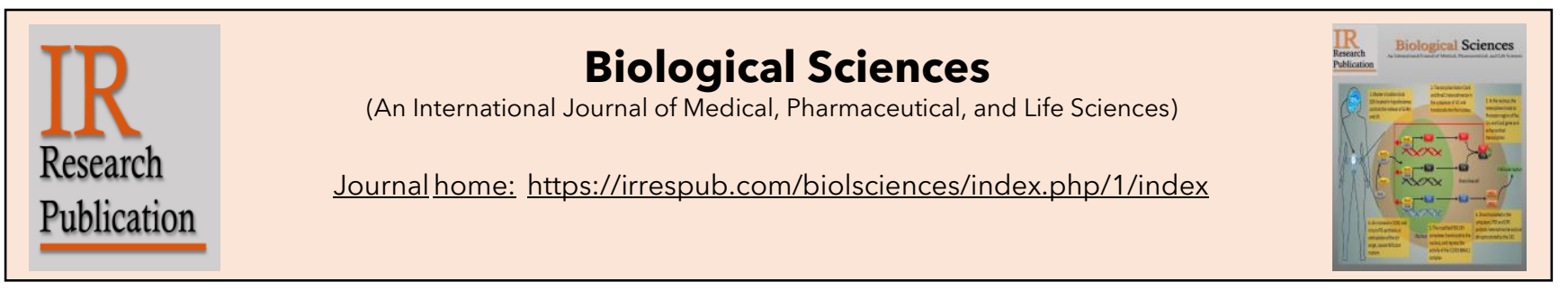

\title{
Importance of biological clock epigenetics in the manifestation of polycystic ovary syndrome
}

\author{
Ziaur Rahman1, Mohd Rabi Bazaz1, Tulasi Pasam1', Mani Surya Kumar¹, Manoj P. \\ Dandekar ${ }^{1 *}$
}

${ }^{1}$ Department of Pharmacology \& Toxicology, National Institute of Pharmaceutical Education and Research (NIPER), Balanagar, Hyderabad, Telangana, India

\section{ARTICLE HISTORY}

Received: 19-04-2021

Revised: 21-04-2021

Accepted: 21-04-2021

Online: 24-04-2021

\section{KEYWORDS}

Polycystic ovary syndrome

Epigenetics

Circadian rhythm

DNA methylation

Histone modification

MicroRNA

\section{ABSTRACT}

In recent times, the incidence of polycystic ovary syndrome (PCOS) increases at an alarming rate. It is ascribed to the metabolic and endocrine imbalance, which subsequently adversely impacts the fertility of women. Growing evidence indicates the crucial role of circadian biology in the development and progression of PCOS. Here, we describe the role of epigenetic machinery related to circadian genes (Clock, Bmal, Per, and Cry) on insulin resistance and hyperandrogenism components of the PCOS. We comprehensively discuss the interconnection between the genetics of circadian rhythm and PCOS pathophysiology. Deeper insights into the epigenetic changes of circadian genes may open new routes for the epigenetic regulation of ovarian physiology and PCOS.

\section{Introduction}

Polycystic ovary syndrome (PCOS) is an endocrine and metabolic ailment in women characterized by hyperandrogenism, ovulatory disorder, polycystic ovarian morphology (PCOM), and hyperinsulinemia (1). In premenopausal women, PCOS occurrence ranges from $6 \sim 20 \%$, indicating the endocrine and metabolic origin of the sickness at reproductive age

\section{*Address for correspondence}

Department of Pharmacology \& Toxicology, National Institute of Pharmaceutical Education and Research (NIPER), Balanagar, Hyderabad, Telangana, India Email: manoj.dandekar@niperhyd.ac.in

DOI: http://dx.doi.org/10.55006/biolsciences.2021.1107 Published by IR Research Publication; Rahman Z et al (C) 2021 by Biological Sciences is licensed under CC BY ${ }_{40}(0)$ (i) of women $(2,3)$. The infertility rate is $70-80 \%$ in women with PCOS (4). Multiple studies reported that women with PCOS have a 2.7-fold increased risk for developing endometrial cancer. However, the risk of ovarian and breast cancer remains unchanged (5). The risk factors for PCOS include genetic changes, insulin resistance (IR), hyperinsulinemia, hyperandrogenism, ovarian follicular maturation arrest, gonadotropic derangements, and obesity $(1,3)$. The daily $24 \mathrm{~h}$ sleep-wake cycle is maintained by circadian rhythm, involved in directing various endogenous physiological, metabolic functions, and genetic expressions (6). The circadian rhythm controls the metabolic activity, as distressed circadian rhythm is connected with various metabolic syndromes like diabetes, insulin resistance, and obesity (7). Sleep disturbances and sleep apnoea increase the PCOS incidence by two-fold (8). The two well-known biomarkers of the circadian cycle are cortisol and melatonin, as cortisol peaks in the early morning and melatonin levels rise in the night. Interestingly, 


\begin{abstract}
Abbreviations: AR: Androgen receptor; Bmal: Brain and muscle ARNT-like protein; BMI: Body mass index; CK: Casein kinases; Clock: Circadian locomotor output cycles kaput; CREB: CAMP response element binding protein; Cry: Cryptochrome; DAX: Nuclear receptor subfamily; DNMT: DNA methyltransferase; EPHX: Epoxide hydrolase; ESR: Estrogen receptor; EZH: Zeste homolog ; FOXL: Forkhead Box L; FSH: Follicle stimulating hormone; GLUT: Glucose transporter type; GnRH: Gonadotropin-releasing hormone; HAT: Histone acetyltransferases; HDAC: Histone deacetylase; HDM: Histone demethylase; HFD: High-fat diet; HGC: Human chorionic gonadotropin; HMGA: high-mobility group AT; HMT: Histone methyl transferase; HOMA-IR: Homeostatic model assessment for insulin resistance; HSD3B: 3-beta-hydroxysteroid dehydrogenase; IER: Immediate early response; IGF1R: Insulin like growth factor 1 receptor; INSR: Insulin receptor; IR: Insulin resistance; IRS: Insulin receptor substrate; LH: Luteinising hormone; MeDIP: Methylated DNA immunoprecipitation; miRNA: MicroRNA; MTNR: Melatonin receptor; NAD: Nicotinamide-adenine dinucleotide; NCOR: nuclear corepressor; NPAS: Neuronal Per-Arnt-Sim domain-containing protein; ORP: Oxysterol-binding protein-related protein; PCOM: Polycystic ovarian morphology; PCOS: Polycystic ovary syndrome; Per: Period; PPAR $\square$ : peroxisome proliferator-initiated receptor gamma; PTEN: Phosphatase and tensin homolog; SCN: Suprachiasmatic nuclei; SF: Steroidogenic factor; SNP: Singlenucleotide polymorphism; SRD5A: 3-oxo-5 $\alpha$-steroid 4-dehydrogenase; STAR: Steroidogenic acute regulatory protein; T2DM:Type 2 diabetes mellitus
\end{abstract}

women with PCOS showed an elevated level of melatonin in the morning, which indicates a disturbed circadian cycle. The rise of cortisol levels in PCOS subjects might indicate stress-mediated hyperactivity of the hypothalamus-pituitary-adrenal (HPA) axis (9). A typical component of PCOS is a disturbance of neuroendocrine and endocrine function, suggesting sporadic cycles and timing of ovarian steroid hormone discharge (10). Changes in the clock gene expression in the ovary may occur due to the hormonal imbalances associated with these disorders (11). Hyperandrogenemia prompts a dramatic change in the timing system, especially clock gene expression in the ovarian follicle and liver (12). This impact on the timing of ovarian clock gene expression may intensify the adverse effects of abundant androgen on key segments of the steroid biosynthetic and ovulatory response pathways (13). Dysfunctional epigenetic machinery has been noted as a pertinent factor in several diseases such as obesity and diabetes (14), and prostate cancer (15). PCOS, being a common denominator for both reproductive and metabolic abnormalities, may also be epigenetically regulated $(16,17)$. Emerging studies suspected the role of circadian epigenetic in the development of PCOS (18-22). A higher level of global DNA methylation was reported in PCOSoverweight patients (23). miRNA is expressed differently in PCOS linked with several other mechanisms such as insulin signaling, inflammation, adipogenesis, and hyperandrogenemia (24). In PCOS, ovarian dysfunction with hyperandrogenism is associated with the alteration of HDAC3. Several PPAR agonists such as pioglitazone and rosiglitazone significantly mitigate hyperandrogenism and improve ovulation rates in PCOS women. Treatment with PPAR agonist also suggested resuming the normal ovarian function. Thus, downregulation of PPARY1 expression in the granulosa cells (GCs) and induction of ovarian dysfunction in PCOS patients may be due to hyperandrogenism. The epigenetic alterations of PPARY1 may lead to ovarian dysfunction induced by hyperandrogenism. However, since epigenetic changes in the circadian genes with respect to PCOS incidence are poorly discussed, herein we describe the interconnection of these two systems in the development and progression of PCOS.

\section{Epigenetics}

The altered epigenetic programming has been associated with various diseases, including diabetes (14) and prostate cancer (15). Since PCOS is concurrently seen with both reproductive and metabolic abnormalities $(16,17)$, the epigenetic mechanisms may be critical in this phenomenon. Epigenetic changes are generally assessed by DNA methylation, histone modifications, and RNArelated silencing (25). Aberrations in the epigenome contribute to numerous ailments etiology, both prenatal and postnatal life (26).

\section{DNA Methylation}

DNA methylation can be presented as a biomarker for epigenetic modification. Epigenetic alteration by DNA methylation in the mammalian genome includes methyl group switch at the cytosine C5 position to produce 5-methylcytosine. Noteworthy, a massive number of DNMTs have been differentially methylated in adipose tissue of women with PCOS (27). The unaltered total methylation was reported in PCOS patients with the global DNA methylation examinations on peripheral blood leukocytes (28). In further studies, higher global methylated DNA levels in PCOS patients and also harbored a bounty of additional hypermethylated CpG locales. Thus, DNA methylation may enhance the function of a gene in PCOS ovary granulosa cells (23). The genome-wide methylated DNA immunoprecipitation (MeDIP) has been used to identify abnormally methylated genes in patients with PCOS. Seventy-nine genes were abnormally methylated in PCOS-non-IR versus PCOS-IR patients, and 40 genes were abnormally methylated in PCOS sufferers than healthy controls $(28,29)$. Moreover, hyperandrogenism has been connected with the methylation status of genes indispensable for ordinary reproduction and ovarian capacity. For instance, a study carried out in hyperandrogenic females revealed 2 hypermethylated and 5 
hypomethylated $\mathrm{CPG}$ sites in the PPARQ1 and nuclear corepressor 1 (NCOR1) promoter regions (30). In another study, Sang et al. (2014) determined the methylation degree of each $\mathrm{CpG}$ site in the promoter of epoxide hydrolase1 (EPHX1), 3-oxo-5 $\alpha$ steroid 4-dehydrogenase (SRD5A1), and CYP11A1 in 64 peripheral blood samples. They found a connection between methylation of the EPHX1 promoter with PCOS, proposed a key role of methylation in PCOS (31).

\section{Histone modifications}

Histone deacetylase (HDACs) and histone acetyltransferase (HATs) are key enzymes that influence DNA transcription (32). Chen and Fang (2018) revealed increased STAR production for the increased ovarian and adrenal androgen in PCOS patients (33). In PCOS ovaries, Jansen et al. (2004) identified down-regulated HDAC3 and increased PPARQ. Valproic acid, which acts as an HDACinhibitor and PPARQ agonist, exhibits PCOS-like features such as hyperandrogenism and polycystic ovary $(34,35)$. An increase in expression of HDAC6 is associated with the IR in PCOS through phosphatase and tensin homolog (PTEN) deacetylation. Tian et al. (2015) observed that Chinese natural remedy eases hyperandrogenism of PCOS rats via regulating PPARD1 and HDAC3 expression in the ovaries of PCOS rats (36). Several studies manifested that IR can be reversed through HDAC inhibitors that ought to be a plausible strategy in the remedy of PCOS (37-39). Overweight is one of the predominant contributing components for PCOS (1). A study carried out by Xue et al. (2018) suggested that $99 a / E H M T 2$, a histone methyltransferase, was markedly reduced in the liver of db/db mice and high-fat diet (HFD)-fed mice.

\section{Non-coding RNA}

miRNAs are regulatory small ssRNA molecules (2125 nucleotides) involved in the post-transcriptional regulation of $m R N A$ s by binding with the 3'-UTR of a target mRNA resulting in degradation or translational inhibition of the transcript $(40,41)$. Any specific miRNA can modulate several target genes expression and function (42). Thus, they are involved in numerous physiological and pathological conditions, including cell proliferation, apoptosis, development, and carcinogenesis (43). Several studies demonstrated the significance of miRNAs in PCOS (22). A study carried out by Hossain et al. (2013) recommends that miRNAs are differentially regulated in hyperandrogenism, a situation possibly involved in the dysregulation of steroid hormone receptors and intra-ovarian factors, and that miRNAs may additionally be involved in the etiology of PCOS (44). miRNA expression in the blood and follicular fluid of PCOS patients involved in the disease phenotype's progression (45). Long et al. (2014) confirmed that miR-222, miR-146a, and miR-30c might additionally serve as novel biomarkers for PCOS diagnosis. A genome-wide association study recently concluded high-mobility group AT-hook 2 (Hmga2) and rab5b as PCOS candidate genes and are anticipated to be the target genes of miR-132 and miR-320. Sang et al. (2013) postulated that decrease miR-132 and miR-320 expression levels in the follicular fluid of PCOS sufferers might also influence Hmga2 and rab5b gene expression. They also observed that miR-132 and miR-320 are substantially related to PCOS, and the expression levels of both are lower in PCOS patients (46). Comparison of the expression profiles confirmed that miR-30a was markedly up-regulated, while miR140 and let-7b had been substantially downregulated in follicular fluid pools from patients with PCOS $(n=30)$. Consequently, down-regulation of let-7b in ovarian follicles may result in deregulation of the TGF- $\beta$ signaling pathway and subsequently make contributions to PCOS development (47). Scalici et al. (2016) confirmed that in PCOS, estrogen receptor $\alpha$ expression changes which may impact miR-140 expression in ovarian follicles (47) contrarily. In PCOS ovaries, granulosa cells have more excellent proliferation rates associated with ovarian dysfunction (48). Jiang et al. (2015) demonstrated that miR-93 is excessively expressed in PCOS ovaries involved in promoting granulosa cell proliferation (49). Genes involved in IR and hyperandrogenism are getting altered by miRNAs from the principal contributing aspect of PCOS development.

An accelerated expression of various genes coding for steroidogenic enzymes was seen in ovaries of PCOS patients, which subsequently increases the production of the androgen (50). Different candidate genes engaged with androgen biosynthesis, transport, activity, and their regulation, in PCOS and functional hyperandrogenism are CYP17; steroidogenic factor 1: SF1; nuclear receptor subfamily: DAX-1; steroidogenic acute regulatory protein: STAR; CYP11A1, CYP11B2, CYP21, 3-beta-hydroxysteroid dehydrogenase: HSD3B2; HSD17B, CYP19, androgen receptor: AR; Estrogen receptor: ESR1; LHB; FSHB; FSH receptor; $\mathrm{GnRH}$ receptor; dopamine receptor; SHBG; glucocorticoid receptor and UDPglucuronyltransferase 2B15 (51). Numerous miRNAs in human follicular liquids directs specific gene associated with steroidogenesis (Table 1) and play an essential function in PCOS progression (46). A key steroid biosynthetic enzyme, CYP11A1, is an expected target of miR-24-3p, and diminished levels of miR-24-3p may consequently lead to an enhanced expression of CYP11A1 and hyperandrogenism (52). A miR-29a-3p low level may intensify the hormonal imbalance deduced in PCOS by targeting STARD3 and AR, two anticipated target 
genes of miR-29a-3p (52). ESR1 targets various miRNAs, including miR-193b, miR-222, and miR$520 c-3 p$, among the other target genes, and others play out an absolute position in reproductive steroidogenesis approaches (46). Besides, Sang et al. (2013) saw miR-132, miRNA-24, miR-520c-3p, miRNA-222, and miR-320 controlled estradiol secretion. The mimic of miR-24 lowered estradiol secretion, and its inhibitor sped up estradiol secretion. miR-132, miR-320, miR-520c-3p, and miR222 mimics increased estradiol secretion, and their inhibitors diminished estradiol secretion, and other miRNAs did not alter estradiol concentration (46).

At the cellular level, IR resulting from dampening phosphorylation of the insulin receptor substrate (IRS-1/IRS-2) in response to insulin tyrosine stimulation (53) and related downstream signalling exercises (translocation of glucose transporters to the cell membrane) in glucose-processing cells (54). Stress and inflammatory signaling activities (JNK activation) result in serine phosphorylation (instead of tyrosine) of insulin receptor proteins, inhibiting insulin signaling (cellular IR) (55). miRNAs-regulated genes are engaged with metabolic processes, such as insulin synthesis, secretion, sensitivity, and pancreatic ß-cells differentiation (Table 1) (56). For example, the overexpression of miR-29 prompted insulin obstruction in 3T3-L1 adipocytes (57), whereas miR-320 sped up insulin sensitivity (58), miR-30d inhibited insulin expression (59). Yuan and Tan (2017) recommended that miR-320 inhibits IR in patients with PCOS via regulating the ERK1/2 signaling pathway (60). Regardless of miR-143 being a positive controller of adipogenesis, miR143-145 group knockout mice have been blanketed from overweight prompted $I R$, while restrictive overexpression of miR-143 results in exacerbated IR in diet-induced obesity. MiR-143 may also intensify IR by enhancing the degeneration of oxysterolbinding protein-related protein (ORP), a positive controller of Akt signaling (61). Experiments on transgenic mice have demonstrated that let-7 is a robust controller of glucose metabolism and peripheral IR by means of targeting IRS-2, insulin receptor (INSR), and insulin-like growth factor 1 receptor (IGF1R) in the liver and skeletal muscle (62). Shi et al. (2013b) revealed that overexpression of miR-181b slows down the signalling pathways $\mathrm{PI} 3 \mathrm{~K} / \mathrm{AKT}$ and MAPK/ERK1, which is involved in IR (63). A study by $\mathrm{Wu}$ et al. (2014) shows that enhanced expression of miR-93 as observed in PCOS subjects' adipose tissue is positively correlated with IR (64). Subsequently, Chen et al., (2013) study unveiled that miR-93 overexpression outcomes in glucose transporter type 4 (GLUT4) downregulation in adipocytes via GLUT4 3'-UTR direct targeting, whilst inhibition of mir-93 activity led to sped up GLUT4 expression, showing GLUT4 dysregulation performs a central position in IR and PCOS (65). Furthermore, studies have demonstrated that miR-27b, miR-21, miR-155, and miR-103 are associated with regulating follicular development, androgen synthesis, and insulin sensitivity-related signaling pathways, which may additionally furnish a new target for the diagnosis and therapy of PCOS $(60,66)$

\section{Epigenetic revamping of the biological clock in PCOS pathogenesis}

Modulation of the circadian Clock gene led to the progression of diabetes, obesity, and metabolic disorders (67). Some studies showed the involvement of circadian genes in the pathogenesis of PCOS (68). The Clock mutant mice show hyperglycaemia, overweight and metabolic disorders (69). The Per1/Per2 double knockout mice and Cry1/Cry2 double knockout mice were intolerant to glucose $(70,71)$. Mice without Bmal1 displayed similar intolerance to glucose and altered gluconeogenesis (72). Additionally, the standard circadian rhythm of elevated insulin sensitivity was completely nullified in global Bmal1 knockout mice (73). Muscle-specific BMAL1 inactivation and muscle CLOCK's ensuing disturbance cause a condition of diminished metabolic adaptability, described by muscle IR and adjusted glucose metabolism (7). It has been reported that siRNA-mediated inhibition of the clock gene interferes with the expression of aromatase (p450 arom) mRNA and, consequently, estrogen production (74). Genetic variant in CLOCK single-nucleotide polymorphism (SNP) rs1801260 $(3111 \mathrm{~T} / \mathrm{C})$ is connected with anomalies of lipid and glucose metabolism in the premenopausal female with PCOS, that underpins a capacity for the circadian clock in the progression of the metabolic disorder (67). Furthermore, hyperandrogenism, a frequent characteristic of PCOS, has been observed to alter the timing of clock gene expression in the liver and ovarian follicle in rats; both tissues are related to metabolic and reproductive function, respectively (12). Gonadotropin-releasing hormone (GnRH) neurons also express clock genes (75), which may be contributed to rhythmically via kisspeptin (76). The kisspeptin gene and its receptor have been linked with PCOS, and it is a potential target of endocrine and metabolic syndrome (77). Administration or deprivation of melatonin, a wellknown marker of the circadian system, showed changes in the CYP17A1 expression and steroidogenesis in the ovary (78). The robust affiliation between SNP rs10830963 in the melatonin receptor (MTNR)1B gene (79) and SNP rs2119882 in the MTNR1A gene (80) and fasting glucose and insulin release and homeostatic model assessment for insulin resistance (HOMA-IR) point out that SNP, rs10830963 and SNP rs2119882 may be causative to the PCOS.

\section{The circadian biology of the ovary}




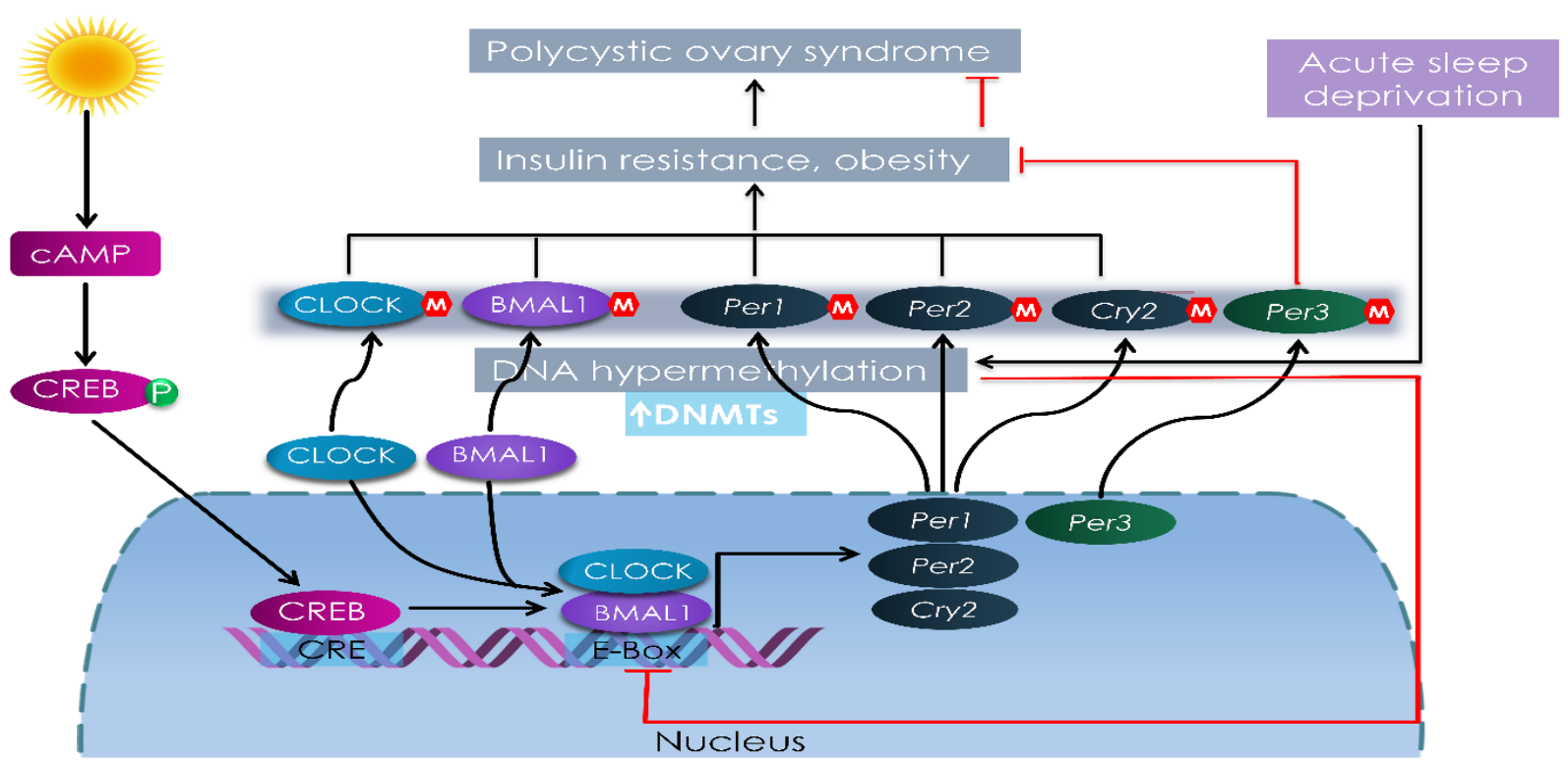

Figure 1. Schematic representation of circadian genes involved in the development of PCOS. Daylight favors the binding of CREB to the CRE situated within the target sequence. This coupling leads to CLOCK and BMAL1 heterodimer translocation into the nucleus and their interaction to the E-box promoter site of the target gene (Per1, Per2, Per3, Cry1, and Cry2). Enhanced expression of DNMTs causes hypermethylation of circadian genes involved in $\mathrm{IR}$, and obesity adds to PCOS advancement. Hypermethylation of Per3 is contrarily connected with IR and weight gain. Intense lack of sleep causes Hypermethylation of the circadian genes, which intern diminishes their expression.

The suprachiasmatic nucleus (SCN) in the hypothalamus regulates the mammalian clock $(81,82)$. The circadian rhythm is a molecular clock comprising the transcriptional/translational feedback loops that manage the small variety of clock genes expression, which includes circadian locomotor output cycles kaput (Clock), brain and muscle ARNT-like protein 1 (bmal1), period1 (per1) andcryptochrome1 (cry1) (48,83). PER and CRY proteins heterodimerized after they get translated to the cytoplasm and then phosphorylated with casein kinases (CK1). The phosphorylated PER and CRY complexes get translocated into the nucleus and suppress the CLOCK: BMAL1 complex. The expression of the clock gene in the ovaries might play a key role in ovulation. Prostanoid signalling is suggested to be critical in setting the circadian clock in the ovary and the time of ovulation $(84,85)$. The transcription of COX2 is partly regulated via E-box DNA binding sequences that are recognized targets of the CLOCK: BMAL1 transactivator complex, therefore CLOCK: BMAL1 heterodimer may bind to and prompt COX2 transcription $(86,87)$. The increased COX2 expression is also connected with the surge of luteinizing hormone (LH) via augmented prostaglandin synthesis, which may enable follicular rupture. Besides this, it has been pointed out that the circadian clock regulates steroidogenesis $(88,89)$. In ovariectomized rats, LH and follicle-stimulating hormone (FSH) triggered the expression of PER1 and PER2 (90). The follicular cells in the ovary express receptors for melatonin and modulate the ovarian clock. The ovulation timing not only depends on the SCN dependent secretion of $\mathrm{LH}$ but also gonadotropins timing which is set through the ovarian clock (91).

\section{DNA Methylation}

The transcripts for the centre oscillator factors such as ARNTL, CLOCK, PER1, PER2, and CRY1 have existed in the ovary of rodents (92). Herein, we describe the fundamental role of circadian genes in the advancement of PCOS. Studies have demonstrated the lower BMAL1 expression in the granulosa cells of women with PCOS. The aromatase expression and estrogen synthesis were downregulated in KGN cells following BMAL1 knockdown while upregulated in cells overexpressing BMAL1 (68). Blockade of CREB signaling showed a colossal decrease in arrhythmic phenotype and light-evoked clock entrainment (93). CREB methylation levels positively correlated with body mass index (BMI) (94). The long-term shift worker displays weight problems and metabolic syndrome risk, which may be associated with the hypomethylation of the Clock gene promoter and Cry2 hypermethylation in peripheral blood DNA (18). Further, sleep disturbances in the form of obstructive sleep apnoea and daytime sleepiness have been seen in females with PCOS (95). Cedernaes et al. (2015) also noted that lack of sleep resulted in the augmentation of promoter methylation and diminished translation of circadian genes in several tissues. They showed expanded methylation of transcription-regulating areas of Per1 
and Cry 1 in adipose tissue and decreased gene expression of Cry1 and Bmal1 in skeletal muscle. Centre clock gene hypermethylation is connected to IR in people (Figure 1) (19), which is one of the essential contributing factors for PCOS progression (96). boxes and prompts its transcription (Figure 2). The circadian difference in insulin sensitivity involved CLOCK/BMAL1 and Sirt1. Circadian disruption decreases the hepatic BMAL1 and Sirt1 and induces IR (21). Zhang et al. (2016) also showed the consequences of BMAL1 on oestrogen synthesis in

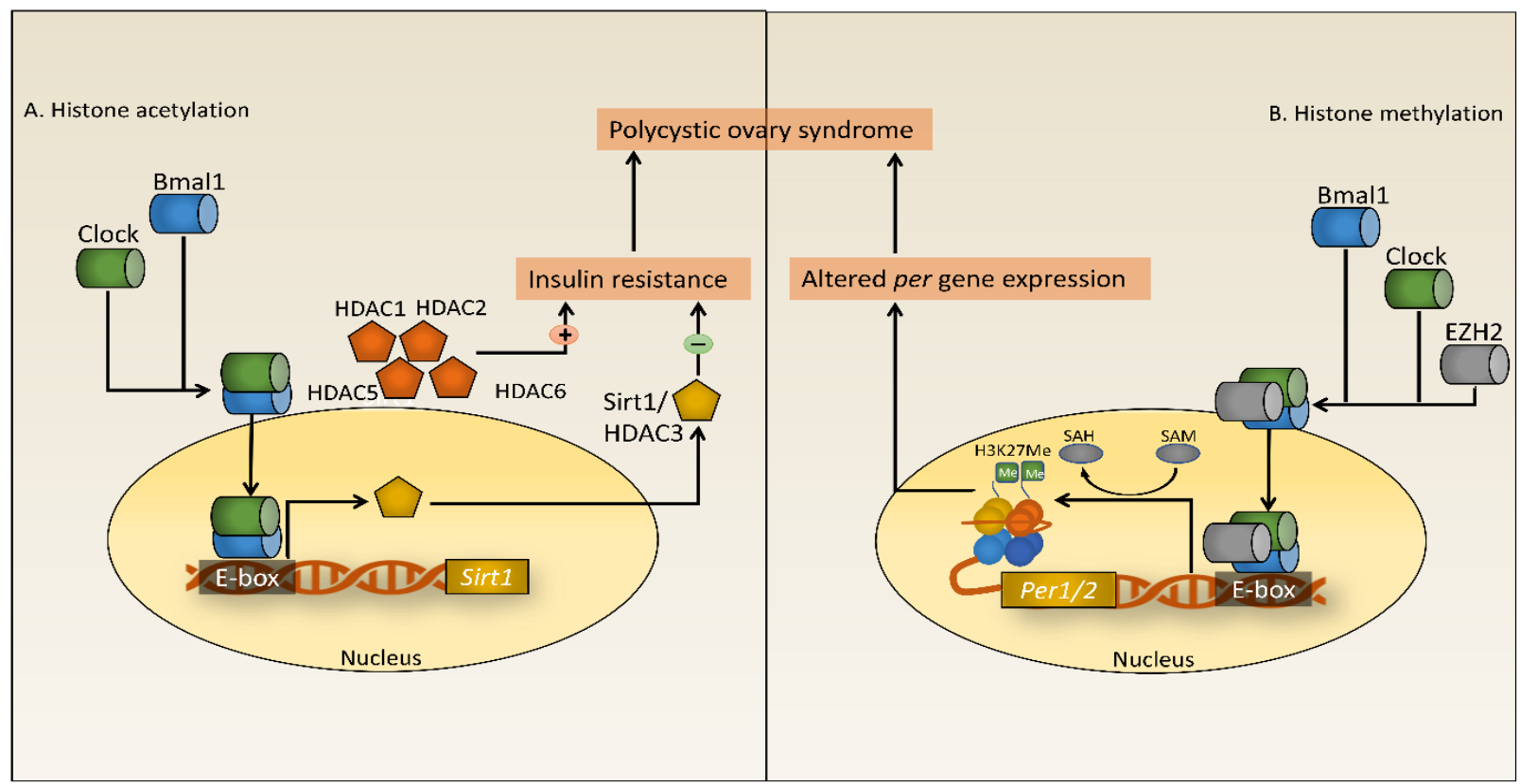

Figure 2. Histone modifications in circadian genes in the progression of PCOS. A: Histone acetylation: CLOCK/BMAL1 heterodimer binds to the Sirt1 (HDAC3) promoter region containing E-box and activates its transcription. Resultant Sirt1 reduces IR. Other HDACs, including HDAC1, HDAC2, HDAC5, and HDAC6, promote IR resulting in PCOS; B: Histone methylation: The histone methyltransferase, EZH2, interacts with CLOCK-BMAL1 complexes and is recruited to the Per1/2 promoters, where it catalyzes the methylation of histone $\mathrm{H} 3$ at lysine 27 (H3K27), resulting in transcriptional repression and per gene expression alteration which contributes to PCOS progression.

\section{Histone modification}

A focal component of the circadian pacemaker CLOCK protein is taking action like HAT, which causes acetylation of histone proteins and nonhistone proteins (20). Active enhancer markers like H3K27Ac and H3K9Ac have been demonstrated to be rhythmic and related to clock gene expression (97). At the Clock loci, rhythmic histone acetylation commonly intervened by means of p300 and CBP HATs (98). Overexpression of HDAC5 in mouse fibroblasts affects the transcriptional rhythms of clock genes. HDAC5 overexpression on the Lys-537 diminishes BMAL1 acetylation, and pharmacological modulation of HDACs of class lla expands BMAL1 acetylation (99). The sirtuins (Sirt1), a unique class III HDACs, have displayed extensive investigational momentum (100). Sirt1 manages the circadian epigenetic via H3K9 deacetylation, acetylation of Bmal1 and Per2 (101-103). The role of Sirt1 is well proven in body weight, cardiovascular problems, and diabetes (104-106). The importance of Sirt1 has also been demonstrated in the immune system, inflammation, and insulin metabolism (107). Zhou et al. (2014) unveil that CLOCK/BMAL1 binds to the Sirt1 promoter vicinity containing the two E- human chorionic gonadotropin (HGC). They suggested the importance of BMAL1-SIRT1-JNK feedback mechanisms in the PCOS progression (68). The process of histone methylation is important in the regulation of the circadian clock (Figure 2). Interaction occurs between zeste homolog 2 (EZH2) a histone methyltransferase, CLOCK and BMAL1 and complex forms which subsequently recruited to the promoters of Per1 and Per2, where it catalyses the H3K27 methylation, generally considered as a sign of transcriptional suppression [95]. Ma et al., (2017) demonstrated that androgens acts via PI3K/Akt pathway phosphorylate and repress the action of EZH2, which recommends the connection between histone methylation, circadian clock and PCOS (108).

\section{Circadian miRNA}

miRNAs may play an irreplaceable role in modulating the circadian clock (Figure 3 ). The dysregulated miRNA expression showed a remarkable change in the circadian timing and output (Table 1) (109). miR-219 and miR-132 are the two brain explicit miRNAs that majorly impacted the 


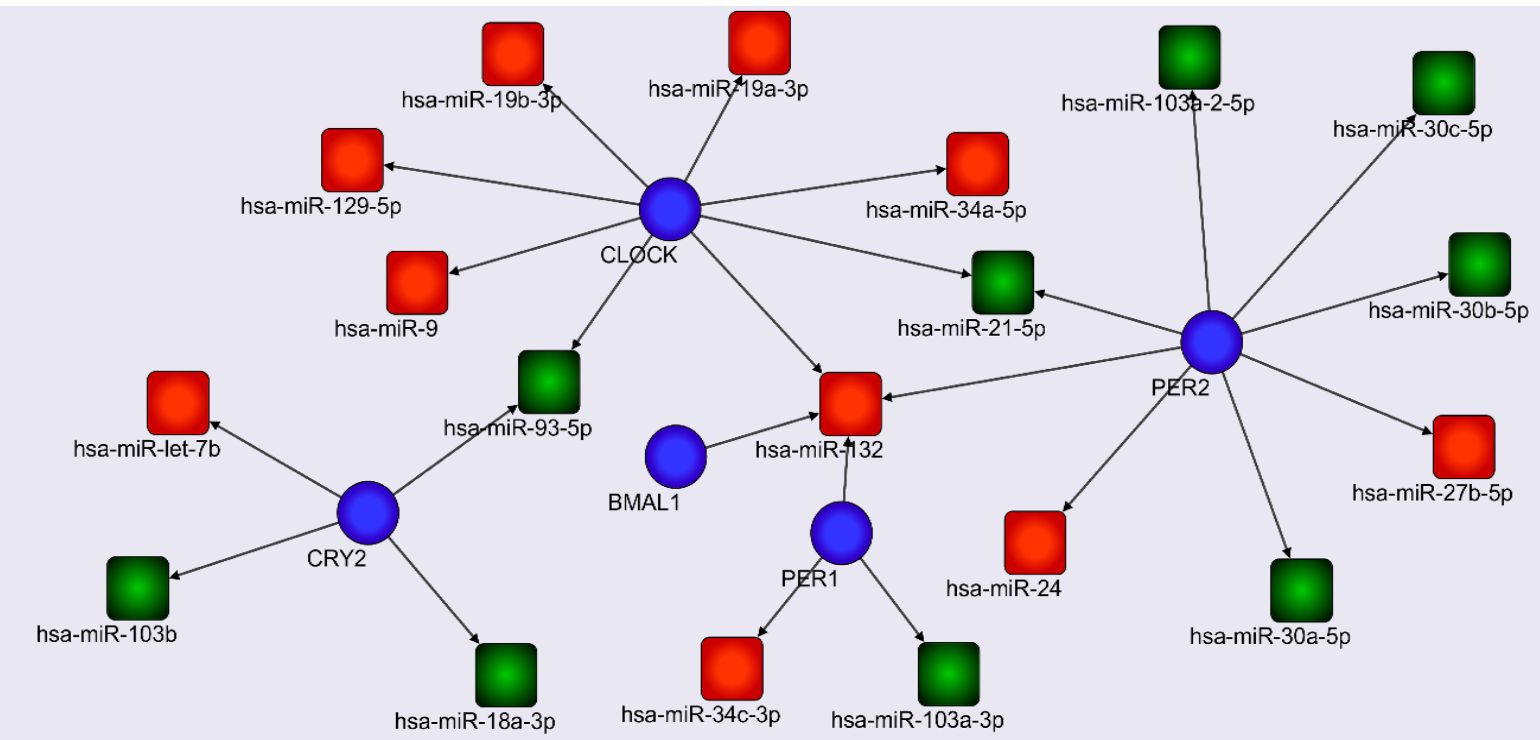

Figure 3. miRNA networking of circadian gene and miRNAs implicated in PCOS. Green: upregulated miRNAs; Red: downregulated miRNAs; Blue: circadian gene. Network plotted to utilize interaction table from mirwalk 2.0 and visualized by Cytoscape v3.6.0

SCN core located circadian clock (110). Overexpression of miR-132 showed an expanded CLOCK/BMAL, and $\mathrm{K}+$ /forskolin instigated mper 1 transactivation (111). The miR-132 transgenic mice showed the diminished light-prompted resetting of behavioral rhythms (112). Sang et al. (2013) study unveiled that miRNA-132 is substantially related to PCOS. Moreover, diminished levels of miR-132 were noticed in gestational diabetes mellitus, suggesting miR-132 may regulate insulin secretion $(46,112)$. Similarly, the involvement of the miR-93 was reported in the circadian mechanism by targeting Clock and Cry2 genes (113). In PCOS-affected women, increased miR-93 expression (65). miR-24$3 p$ was observed to regulate a key steroid biosynthetic enzyme, CYP11A1. The diminished levels of miR-24-3p might consequently lead to an elevated CYP11A1 expression that ultimately results in hyperandrogenism and PCOS. A forkhead transcription aspect encoded by FOXL2 is essential for the development of the ovary (114). In cultured human granulosa cells, overexpression of miR-30a promotes expression of immediate early response 3 (IER3), cyclin D2, and BCL2A1, by means of forkhead Box L2 (FOXL-2) suppression (59). Conditional knockout of FOXL-2 showed an elevated androgen production by theca cells and granulosa cells and morphological transformation such as in PCOS $(47,115)$. The reduced expression of miRNAs $146 a$ and $146 \mathrm{~b}$ and elevated expression of activated NF$\mathrm{kb}$ correlated with the circadian disruption (116). The miR-146a serum level is negatively related to testosterone level, which may serve as a novel biomarker for PCOS analysis (117). Let-7b is also involved in controlling the circadian oscillation and is predicted to target cry2 (116). Furthermore, it has been proven that down-regulation of let-7b in the follicles in the ovary could lead to deregulation of the TGF- $\beta$ signaling pathway that further leads to susceptibility to PCOS (47). The Per3a circadian gene is also proposed as a novel target of miR-103 (118). Additionally, the expression of miR-103 in granulosa cells reduces obesity and PCOS.

\section{Conclusion and future perspectives}

The disturbed epigenetic programming has been demonstrated in several human diseases $(14,124)$. The changes in core circadian genes are associated with the development of obesity, diabetes, and metabolic syndrome in mice (67). Recently, the importance of circadian genes in the development of PCOS is growing (68). Several studies have stated that the epigenetic modifications of circadian genes in the progression of IR and hyperandrogenism, which is also contributed to PCOS. Scientific evidence suggests that circadian-related epigenetic changes triggered by circadian miRNAs and other epigenetic modifiers are highly correlated with IR, hyperandrogenism, and PCOS pathogenesis. Thus, the importance of circadian epigenetics is becoming highly relevant. A growing body of evidence proposed several epigenetics-based mechanisms in the pathogenesis of PCOS. For instance, the DNA methylation, histone modifications, and miRNA-related alterations of circadian genes are well reported in the PCOS. This review has also generated few questions as below i) do DNA methylation, histone modifications, and miRNA-related alterations in circadian genes together find a common underlying mechanism for the development of PCOS; ii) what is the possibility of crosstalk between circadian miRNAs and the circadian gene epigenetic modifiers for the etiopathogenesis of the PCOS; and iii) what is the 
Table 1. Role of miRNAs in PCOS

\begin{tabular}{|c|c|c|c|c|c|}
\hline MiRNA & Location & Target gene & Expression & Function & Reference \\
\hline \multicolumn{6}{|c|}{ miRNAs regulating steroidogenesis } \\
\hline miR-24-3p & $\begin{array}{l}\text { Follicular fluid } \\
\text { Blastocyst }\end{array}$ & CYP11A1 & Down & $\begin{array}{l}\text { Decreases androgenism, } \\
\text { decreases TGF } \\
\text { signalling decreases } \\
\text { estradiol secretion }\end{array}$ & $(119)$ \\
\hline miR-29a-3p & Follicular fluid & $\begin{array}{l}\text { STARD3, } \\
\text { AR, } \\
\text { PTEN }\end{array}$ & Down & $\begin{array}{l}\text { Decreased steroid } \\
\text { production, } \\
\text { Increases cell growth via } \\
\text { inhibition of PTEN }\end{array}$ & $(52)$ \\
\hline $\begin{array}{l}\text { miR-132, miR-320, } \\
\text { miR-222, miR-520c- } \\
\text { 3p }\end{array}$ & Follicular fluid & ESR1 & Down & $\begin{array}{l}\text { Increases estradiol } \\
\text { secretion }\end{array}$ & $(46)$ \\
\hline miR-24 & Follicular fluid & ESR1 & Up & $\begin{array}{l}\text { Decreases estradiol } \\
\text { secretion }\end{array}$ & (46) \\
\hline \multicolumn{6}{|c|}{ miRNAs regulating insulin resistance } \\
\hline miR-29 & Adipocytes & & Up & IR & $(57)$ \\
\hline miR-320 & & $E R K 1 / 2$ & Down & $\begin{array}{l}\text { IR via altering the ERK1/2 } \\
\text { signaling pathway }\end{array}$ & $(58,60)$ \\
\hline miR-30d & & & Up & $\begin{array}{l}\text { Inhibits } \\
\text { expression }\end{array}$ & (59) \\
\hline miR-143 & & Akt & Up & $\begin{array}{l}\text { IR in diet-induced } \\
\text { obesity via affecting Akt } \\
\text { signaling }\end{array}$ & $(61)$ \\
\hline Let-7 & $\begin{array}{l}\text { Skeletal } \\
\text { muscles, } \\
\text { Liver tissue }\end{array}$ & IRS-2 & Down & $\begin{array}{lr}\text { Regulator of } & \text { glucose } \\
\text { metabolism } & \text { and } \\
\text { peripheral IR } & \\
\end{array}$ & $(62)$ \\
\hline miR-181b & & Akt/MAPK & Up & $\begin{array}{l}\text { IR, slow down PI3K/Akt } \\
\text { and MAPK/ERK } 1 \\
\text { pathway }\end{array}$ & (63) \\
\hline miR-93 & Adipocytes & GLUT4 & Up & $\begin{array}{l}\text { Downregulates GLUT4 } \\
\text { and thereby IR }\end{array}$ & $(64,65)$ \\
\hline $\begin{array}{l}\text { miR-21, miR-27b, } \\
\text { miR-103, and miR- } \\
155\end{array}$ & & & & $\begin{array}{l}\text { Involved in the } \\
\text { regulation of follicular } \\
\text { development, androgen } \\
\text { synthesis, and insulin } \\
\text { sensitivity-related } \\
\text { signaling pathways }\end{array}$ & $(60,66)$ \\
\hline \multicolumn{6}{|c|}{ miRNAs regulating circadian gene } \\
\hline miR-132 & Follicular fluid & $\begin{array}{l}\text { Clock } / \text { bmal1 } \\
\text { Per1 and } \\
\text { Per2 }\end{array}$ & Down & $\begin{array}{l}\text { Enhance insulin } \\
\text { secretion (also in T2DM) }\end{array}$ & $(110-112)$ \\
\hline miR-93 & Adipose tissue & $\begin{array}{l}\text { Clock } \\
\text { andcry2 }\end{array}$ & Up & IR & $(113)$ \\
\hline miR-24 & & $\begin{array}{l}\text { Per2, } \\
\text { CYP11A1 }\end{array}$ & Down & $\begin{array}{l}\text { Increased expression of } \\
\text { CYP11A1 and thereby } \\
\text { hyperandrogenism }\end{array}$ & $(120,121)$ \\
\hline miR-30a & $\begin{array}{l}\text { Granulosa } \\
\text { cells }\end{array}$ & $\begin{array}{l}\text { Per2 } \\
\text { FOXL-2 }\end{array}$ & Up & $\begin{array}{l}\text { RepressingFOXL-2 } \\
\text { results in cystic follicles. }\end{array}$ & $(59,121)$ \\
\hline miR-146a & & Per1 & Down & $\begin{array}{l}\text { Increased testosterone } \\
\text { level }\end{array}$ & $(116,117)$ \\
\hline Let-7b & $\begin{array}{l}\text { Ovarian } \\
\text { follicle }\end{array}$ & $\begin{array}{l}\text { Cry2 } \\
\text { TGF-B }\end{array}$ & Down & $\begin{array}{l}\text { TGF- } \beta \text { signaling pathway } \\
\text { deregulation }\end{array}$ & $(47,116)$ \\
\hline miR-103 & $\begin{array}{l}\text { Granulosa } \\
\text { cells }\end{array}$ & Per3 & Up & $\begin{array}{l}\text { Promotes progesterone } \\
\text { release while inhibiting } \\
\text { estradiol release and } \\
\text { also elevate } \\
\text { testosterone level }\end{array}$ & $(118,122,123)$ \\
\hline miR-132 & Follicular fluid & $\begin{array}{l}\text { Clock /bmal1 } \\
\text { Per1 and } \\
\text { Per2 }\end{array}$ & Down & $\begin{array}{l}\text { Enhance insulin } \\
\text { secretion (also in T2DM) }\end{array}$ & $(110-112)$ \\
\hline miR-93 & Adipose tissue & $\begin{array}{l}\text { Clock } \\
\text { andcry2 }\end{array}$ & Up & IR & $(113)$ \\
\hline miR-24 & & $\begin{array}{l}\text { Per2, } \\
\text { CYP11A1 }\end{array}$ & Down & $\begin{array}{l}\text { Increased expression of } \\
\text { CYP11A1 and thereby } \\
\text { hyperandrogenism }\end{array}$ & $(120,121)$ \\
\hline
\end{tabular}


key role of post-transcriptional changes such as phosphorylation, ubiquitination, sumoylation and ADP-ribosylation in histone tails in the progression of PCOS. We believe that epigenetic alteration plays an indispensable role in modulating the circadian clock, which may be a critical step in the pathogenesis of PCOS (109).

\section{Acknowledgments}

The authors want to thank the Department of Pharmaceuticals, Ministry of Chemicals and Fertilizers, Government of India, and National Institute of Pharmaceutical Education and Research (NIPER), Hyderabad, for financial supports. The authors also want to thanks Mr. Irshad for his kind supports.

\section{Conflict of interest}

The authors declare no potential conflicts of interest

\section{References}

1. Azziz R, Carmina E, Chen Z, Dunaif A, Laven JSE, Legro RS, et al. Polycystic ovary syndrome. Nat Rev Dis Prim. 2016;2.

2. Diamanti-Kandarakis E. Role of obesity and adiposity in polycystic ovary syndrome. Int J Obes. 2007;31:S8-13.

3. Lizneva D, Suturina L, Walker W, Brakta S, Gavrilova-Jordan L, Azziz R. Criteria, prevalence, and phenotypes of polycystic ovary syndrome. Fertil Steril. 2016;106(1):6-15.

4. Melo AS, Ferriani RA, Navarro PA. Treatment of infertility in women with polycystic ovary syndrome: approach to clinical practice. Clinics (Sao Paulo). 2015 Nov;70(11):765-9.

5. Harris HR, Terry KL. Polycystic ovary syndrome and risk of endometrial, ovarian, and breast cancer: a systematic review. Fertil Res Pract. 2016;2(1):14.

6. Sahar S, Sassone-Corsi P. Regulation of metabolism: the circadian clock dictates the time. Trends Endocrinol Metab. 2012;23(1):1-8.

7. Dyar KA, Ciciliot S, Wright LE, Biensø RS, Tagliazucchi GM, Patel VR, et al. Muscle insulin sensitivity and glucose metabolism are controlled by the intrinsic muscle clock. Mol Metab. 2014;3(1):29-41.
8. Spinedi E, Cardinali DP. The polycystic ovary syndrome and the metabolic syndrome: a possible chronobiotic-cytoprotective adjuvant therapy. Int J Endocrinol. 2018;2018.

9. Lim AJR, Indran IR, Kramer MS, Yong E. Phenotypic spectrum of polycystic ovary syndrome and their relationship to the circadian biomarkers, melatonin and cortisol. Endocrinol diabetes Metab. 2019;2(3):e00047.

10.Padmanabhan V, Veiga-Lopez A. Developmental origin of reproductive and metabolic dysfunctions: androgenic versus estrogenic reprogramming. In: Seminars in reproductive medicine. (C) Thieme Medical Publishers; 2011. p. 173-86.

11.Amaral FG do, Castrucci AM, Cipolla-Neto J, Poletini MO, Mendez N, Richter HG, et al. Environmental control of biological rhythms: effects on development, fertility and metabolism. J Neuroendocrinol. 2014;26(9):603-12.

12.Sellix MT, Murphy ZC, Menaker M. Excess androgen during puberty disrupts circadian organization in female rats. Endocrinology. 2013;154(4):1636-47.

13.Sellix MT. Circadian clock function in the mammalian ovary. J Biol Rhythms. 2015;30(1):719.

14. Martin-Gronert MS, Ozanne SE. Programming of appetite and type 2 diabetes. Early Hum Dev. 2005;81(12):981-8.

15.Wazen RM, Kuroda S, Nishio C, Sellin K, Brunski JB, Nanci A. NIH Public Access. 2014;8(9):138595.

16.Xita N, Tsatsoulis A. Fetal Programming of Polycystic Ovary Syndrome by Androgen Excess: Evidence from Experimental, Clinical, and Genetic Association Studies. J Clin Endocrinol Metab. 2006;91(5):1660-6.

17.Li Z, Huang H. Epigenetic abnormality: A possible mechanism underlying the fetal origin of polycystic ovary syndrome. Med Hypotheses. 2008;70(3):638-42.

18.Manenschijn L, Van Kruysbergen RGPM, De Jong $\mathrm{FH}$, Koper JW, Van Rossum EFC. Shift work at young age is associated with elevated long-term cortisol levels and body mass index. J Clin Endocrinol Metab. 2011;96(11):1862-5. 
19.Milagro Fl, Gómez-Abellán $\mathrm{P}$, Campión J, Martínez JA, Ordovás JM, Garaulet M. CLOCK, PER2 and BMAL1 DNA methylation: Association with obesity and metabolic syndrome characteristics and monounsaturated fat intake. Chronobiol Int. 2012;29(9):1180-94.

20.Foley JF. Against the CLOCK. Sci Signal. 2008;1(30):ec270-ec270.

21.Zhou B, Zhang Y, Zhang F, Xia Y, Liu J, Huang R, et al. CLOCK/BMAL1 regulates circadian change of mouse hepatic insulin sensitivity by SIRT1. Hepatology. 2014;59(6):2196-206.

22.Sathyapalan T, David R, Gooderham NJ, Atkin SL. Increased expression of circulating miRNA-93 in women with polycystic ovary syndrome may represent a novel, non-invasive biomarker for diagnosis. Sci Rep. 2015;5(November):1-8.

23.Xu J, Bao X, Peng Z, Wang L, Du L, Niu W, et al. Comprehensive analysis of genome-wide DNA methylation across human polycystic ovary syndrome ovary granulosa cell. Oncotarget. 2016;7(19):27899-909.

24.Ilie IR, Georgescu CE. Polycystic ovary syndromeepigenetic mechanisms and aberrant microRNA. In: Advances in clinical chemistry. Elsevier; 2015. p. 25-45.

25.Xie Z, Huang G, Wang Z, Luo S, Zheng P, Zhou Z. Epigenetic regulation of Toll-like receptors and its roles in type 1 diabetes. J Mol Med. 2018;96(8):741-51.

26.Shamsi MB, Firoz AS, Imam SN, Alzaman N, Samman MA. Epigenetics of human diseases and scope in future therapeutics. J Taibah Univ Med Sci. 2017;12(3):205-11.

27.Kokosar M, Benrick A, Perfilyev A, Fornes R, Nilsson $E$, Maliqueo $M$, et al. Epigenetic and Transcriptional Alterations in Human Adipose Tissue of Polycystic Ovary Syndrome. Sci Rep. 2016;6(September 2015):1-17.

28.Yu YY, Sun CX, Liu YK, Li Y, Wang L, Zhang W. Genome-wide screen of ovary-specific DNA methylation in polycystic ovary syndrome. Fertil Steril. 2015;104(1):145-153.e6.

29.Shen H, Qiu L, Zhang Z, Oin Y, Cao C, Di W. Genome-Wide Methylated DNA Immunoprecipitation Analysis of Patients with Polycystic Ovary Syndrome. PLoS One. 2013;8(5):e64801.
30.Qu F, Wang FF, Yin R, Ding GL, El-prince M, Gao $\mathrm{Q}$, et al. A molecular mechanism underlying ovarian dysfunction of polycystic ovary syndrome: Hyperandrogenism induces epigenetic alterations in the granulosa cells. J Mol Med. 2012;90(8):911-23.

31.Sang $Q$, Li X, Wang $H$, Wang $H$, Zhang S, Feng R, et al. Quantitative methylation level of the EPHX1 promoter in peripheral blood DNA is associated with polycystic ovary syndrome. PLoS One. 2014;9(2):1-7.

32.Chrun ES, Modolo F, Daniel FI. Histone modifications: A review about the presence of this epigenetic phenomenon in carcinogenesis. Pathol Res Pract. 2017;213(11):1329-39.

33. Chen Y, Fang S. Potential genetic polymorphisms predicting polycystic ovary syndrome. Endocr Connect. 2018;EC-18-0121.

34.Jansen E, Laven JSE, Dommerholt HBR, Polman J, van Rijt C, van den Hurk C, et al. Abnormal Gene Expression Profiles in Human Ovaries from Polycystic Ovary Syndrome Patients. Mol Endocrinol. 2004;18(12):3050-63.

35.Wood JR, Nelson-Degrave VL, Jansen E, McAllister JM, Mosselman S, Strauss JF. Valproate-induced alterations in human theca cell gene expression: clues to the association between valproate use and metabolic side effects. Physiol Genomics. 2005;20(3):233-43.

36.Tian $Y$, Wong VWS, Wong GLH, Yang W, Sun $H$, Shen J, et al. Histone deacetylase HDAC8 promotes insulin resistance and $\beta$-catenin activation in NAFLD-associated hepatocellular carcinoma. Cancer Res. 2015;75(22):4803-16.

37.Ye J. Improving insulin sensitivity with HDAC inhibitor. Diabetes. 2013;62(3):685-7.

38.Balcerczyk A, Chriett S, Pirola L. Insulin Action, Insulin Resistance, and Their Link to Histone Acetylation. In p. 1-22.

39.Christensen D, Dahllof M. <Title/>. Mol Med. 2011;17(5-6):1.

40.Reza MI, Goel D, Rahman Z, Aamer S. Microrna and Rna Binding Proteins: the Posttranscriptional Regulators of Foxo Expression. J Crit Rev. 2018;5(2):1. 
41.Klotz CL, Jena F. Posttranscriptional regulation of FOXO expression : microRNAs and beyond. $\mathrm{Br} \mathrm{J}$ Pharmacol. 2016;1-19.

42.Lim LP, Lau NC, Garrett-Engele P, Grimson A, Schelter JM, Castle J, et al. Microarray analysis shows that some microRNAs downregulate large numbers of target mRNAs. Nature. 2005 Jan;433:769.

43. Morales S, Monzo M, Navarro A. Epigenetic regulation mechanisms of microRNA expression. Biomol Concepts. 2017 Dec;8(5-6):203-12.

44. Hossain MM, Cao M, Wang Q, Kim JY, Schellander K, Tesfaye D, et al. Altered expression of miRNAs in a dihydrotestosteroneinduced rat PCOS model. J Ovarian Res. 2013;6(1):1.

45.Naji M, Aleyasin A, Nekoonam S, Arefian E, Mahdian R, Amidi F. Differential Expression of miR-93 and miR-21 in Granulosa Cells and Follicular Fluid of Polycystic Ovary Syndrome Associating with Different Phenotypes. Sci Rep. 2017;7(1):1-14.

46.Sang $Q$, Yao Z, Wang $H$, Feng R, Wang $H$, Zhao $X$, et al. Identification of MicroRNAs in human follicular fluid: Characterization of MicroRNAs that govern steroidogenesis in vitro and are associated with polycystic ovary syndrome in vivo. J Clin Endocrinol Metab. 2013;98(7):306879.

47.Scalici E, Traver $S$, Mullet $T$, Molinari N, Ferrières $A$, Brunet $C$, et al. Circulating microRNAs in follicular fluid, powerful tools to explore in vitro fertilization process. Sci Rep. 2016;6(April):1-10.

48.Stubbs SA, Stark J, Dilworth SM, Franks S, Hardy K. Abnormal preantral folliculogenesis in polycystic ovaries is associated with increased granulosa cell division. J Clin Endocrinol Metab. 2007;92(11):4418-26.

49.Jiang L, Huang J, Li L, Chen Y, Chen X, Zhao X, et al. MicroRNA-93 promotes ovarian granulosa cells proliferation through targeting CDKN1A in polycystic ovarian syndrome. J Clin Endocrinol Metab. 2015;100(5):E729-38.

50.McAllister JM, Legro RS, Modi BP, Strauss III JF. Functional genomics of PCOS: from GWAS to molecular mechanisms. Trends Endocrinol Metab. 2015;26(3):118-24.
51.Escobar-Morreale HF, Luque-Ramírez M, San Millán JL. The molecular-genetic basis of functional hyperandrogenism and the polycystic ovary syndrome. Endocr Rev. 2005;26(2):25182.

52.Sï $i^{1 / 2 r e n s e n ~} A E$, Wissing $M L$, Englund $A L M$, Dalgaard LT. MicroRNA species in follicular fluid associating with polycystic ovary syndrome and related intermediary phenotypes. J Clin Endocrinol Metab. 2016;101(4):1579-89.

53. Hotamisligil GS, Peraldi P, Budavari A, Ellis R, White MF, Spiegelman BM. IRS-1-mediated inhibition of insulin receptor tyrosine kinase activity in TNF- $\alpha$-and obesity-induced insulin resistance. Science (80- ). 1996;271(5249):66570.

54.De Alvaro C, Teruel T, Hernandez R, Lorenzo M. Tumor necrosis factor a produces insulin resistance in skeletal muscle by activation of inhibitor $\mathrm{kB}$ kinase in a p38 MAPK-dependent manner. J Biol Chem. 2004;279(17):17070-8.

55. Hotamisligil GS. Inflammation and metabolic disorders. Nature. 2006;444(7121):860.

56. Vivacqua A, Marco P De, Belfiore A, Maggiolini $M$. Recent Advances on the Role of microRNAs in both Insulin Resistance and Cancer. Curr Pharm Des. 2017;23(25):3658-66.

57. He A, Zhu L, Gupta N, Chang Y, Fang F. Overexpression of micro ribonucleic acid 29, highly up-regulated in diabetic rats, leads to insulin resistance in 3T3-L1 adipocytes. Mol Endocrinol. 2007;21(11):2785-94.

58.Chakraborty C, Doss CGP, Bandyopadhyay S, Agoramoorthy $\mathrm{G}$. Influence of miRNA in insulin signaling pathway and insulin resistance: micromolecules with a major role in type-2 diabetes. Wiley Interdiscip Rev RNA. 2014;5(5):697-712.

59.Wang T, Li F, Tang S. MiR-30a upregulates BCL2A1, IER3 and cyclináD2 expression by targeting FOXL2. Oncol Lett. 2015;9(2):967-71.

60. Yuan W-N, Tan L. MicroRNA-320 inhibits insulin resistance in patients with PCOS through regulating ERK1/2 signaling pathway. Biomed Res. 2017;28(11):4946-9.

61.Jordan SD, Krüger M, Willmes DM, Redemann N, Wunderlich FT, Brönneke HS, et al. Obesityinduced overexpression of miRNA-143 inhibits insulin-stimulated AKT activation and impairs 
glucose metabolism. Nat Cell Biol. 2011 Mar;13:434.

62.Zhu H, Shyh-Chang N, Segrè A V, Shinoda G, Shah SP, Einhorn WS, et al. The Lin28/let-7 axis regulates glucose metabolism. Cell. 2011;147(1):81-94.

63.Shi ZM, Wang XF, Qian X, Tao T, Wang L, Chen QD, et al. MiRNA-181b suppresses IGF-1R and functions as a tumor suppressor gene in gliomas. Rna. 2013;19(4):552-60.

64.Wu H-L, Heneidi S, Chuang T-Y, Diamond MP, Layman LC, Azziz R, et al. The Expression of the miR-25/93/106b Family of Micro-RNAs in the Adipose Tissue of Women With Polycystic Ovary Syndrome. J Clin Endocrinol Metab. 2014 Dec;99(12):E2754-61.

65.Chen YH, Heneidi S, Lee JM, Layman LC, Stepp DW, Gamboa GM, et al. Mirna-93 inhibits glut4 and is overexpressed in adipose tissue of polycystic ovary syndrome patients and women with insulin resistance. Diabetes. 2013;62(7):2278-86.

66.Ling H-Y, Hu B, Hu X-B, Zhong J, Oin L, Liu G, et al. MiRNA-21 reverses high glucose and high insulin induced insulin resistance in 3T3-L1 adipocytes through targeting phosphatase and tensin homologue. Exp Clin Endocrinol diabetes. 2012;120(09):553-9.

67.Pernicova I, Akinci B, Prasai M, Baxter P, Scott E. Association between rs1801260 of the circadian gene CLOCK and lipid and glucose metabolism in women with Polycystic Ovary Syndrome. In: Society for Endocrinology BES 2012. BioScientifica; 2012.

68.Zhang J, Liu J, Zhu K, Hong Y, Sun Y, Zhao X, et al. Effects of BMAL1-SIRT1-positive cycle on estrogen synthesis in human ovarian granulosa cells: an implicative role of BMAL1 in PCOS. Endocrine. 2016;53(2):574-84.

69.Turek FW, Joshu C, Kohsaka A, Lin E, Ivanova G, McDearmon $E$, et al. Obesity and metabolic syndrome in circadian Clock mutant mice. Science. 2005 May;308(5724):1043-5.

70.Lamia KA, Papp SJ, Ruth TY, Barish GD, Uhlenhaut NH, Jonker JW, et al. Cryptochromes mediate rhythmic repression of the glucocorticoid receptor. Nature. 2011;480(7378):552.
71.Lamia KA, Storch K-F, Weitz CJ. Physiological significance of a peripheral tissue circadian clock. Proc Natl Acad Sci. 2008;105(39):15172-7.

72.Rudic RD, McNamara P, Curtis A-M, Boston RC, Panda S, Hogenesch JB, et al. BMAL1 and CLOCK, two essential components of the circadian clock, are involved in glucose homeostasis. PLoS Biol. 2004;2(11):e377.

73.Shi S, Ansari TS, McGuinness OP, Wasserman $\mathrm{DH}$, Johnson $\mathrm{CH}$. Circadian disruption leads to insulin resistance and obesity. Curr Biol. 2013;23(5):372-81.

74.Shimizu T, Hirai Y, Murayama C, Miyamoto A, Miyazaki H, Miyazaki K. Circadian Clock genes Per2 and clock regulate steroid production, cell proliferation, and luteinizing hormone receptor transcription in ovarian granulosa cells. Biochem Biophys Res Commun. 2011;412(1):132-5.

75.Mead EJ, Maguire JJ, Kuc RE, Davenport AP. Kisspeptins: a multifunctional peptide system with a role in reproduction, cancer and the cardiovascular system. Br J Pharmacol. 2007 Aug;151(8):1143-53.

76.Nejad SZ, Tehrani FR, Zadeh-Vakili A. The role of kisspeptin in female reproduction. Int J Endocrinol Metab. 2017;15(3).

77.Gorkem U, Togrul C, Arslan E, Sargin Oruc A, Buyukkayaci Duman N. Is there a role for kisspeptin in pathogenesis of polycystic ovary syndrome? Gynecol Endocrinol. 2018;34(2):15760.

78.Maganhin CC, Simões RS, Fuchs LFP, Sasso GRS, Simões MJ, Baracat EC, et al. Melatonin influences on steroidogenic gene expression in the ovary of pinealectomized rats. Fertil Steril. 2014; 102(1):291-8.

79.Li C, Shi Y, You L, Wang L, Chen Z-J. Association of rs10830963 and rs10830962 SNPs in the melatonin receptor (MTNR1B) gene among Han Chinese women with polycystic ovary syndrome. MHR Basic Sci Reprod Med. 2011 Mar; 17(3):1938.

80.Li C, Shi Y, You L, Wang L, Chen ZJ. Melatonin receptor $1 \mathrm{~A}$ gene polymorphism associated with polycystic ovary syndrome. Gynecol Obstet Invest. 2011;72(2):130-4.

81. Hastings $M H$, Reddy AB, Maywood ES. A clockwork web: Circadian timing in brain and 
periphery, in health and disease. Nat Rev Neurosci. 2003;4(8):649-61.

82. Hughes ME, DiTacchio L, Hayes KR, Vollmers C, Pulivarthy $S$, Baggs JE, et al. Harmonics of circadian gene transcription in mammals. PLoS Genet. 2009;5(4).

83.Trombly DJ, Woodruff TK, Ph D, Mayo KE. Role for Transforming Growth Factor Beta Superfamily Proteins in Early Folliculogenesis. Semin Reprod Med. 2009;27(1):14-23.

84.Espey LL, Richards JS. Temporal and Spatial Patterns of Ovarian Gene Transcription Following an Ovulatory Dose of Gonadotropin in the Rat1. Biol Reprod. 2002 Dec;67(6):1662-70.

85.Richards JS, Russell DL, Ochsner S, Espey LL. Ovulation: new dimensions and new regulators of the inflammatory-like response. Annu Rev Physiol. 2002;64(1):69-92.

86.Morris JK, Richards JS. An E-box region within the prostaglandin endoperoxide synthase-2 (PGS-2) promoter is required for transcription in rat ovarian granulosa cells. J Biol Chem. 1996;271(28):16633-43.

87.Liu J, Antaya M, Boerboom D, Lussier JG, Silversides DW, Sirois J. The delayed activation of the prostaglandin $\mathrm{G} / \mathrm{H}$ synthase-2 promoter in bovine granulosa cells is associated with downregulation of truncated upstream stimulatory factor-2. J Biol Chem. 1999;274(49):35037-45.

88.Ratajczak CK, Boehle KL, Muglia LJ. Impaired steroidogenesis and implantation failure in Bmal1-/- mice. Endocrinology. 2008;150(4):1879-85.

89.Alvarez J, Hansen A, Ord T, Bebas P, Chappell PE, Giebultowicz JM, et al. The circadian clock protein BMAL1 is necessary for fertility and proper testosterone production in mice. J Biol Rhythms. 2008;23(1):26-36.

90. He P-J, Hirata M, Yamauchi N, Hashimoto S, Hattori M. Gonadotropic regulation of circadian clockwork in rat granulosa cells. Mol Cell Biochem. 2007;302(1-2):111-8.

91.Sellix MT, Yoshikawa T, Menaker M. A circadian egg timer gates ovulation. Curr Biol. 2010;20(6):R266-7.

92.Chen M, Xu Y, Miao B, Zhao H, Luo L, Shi H, et al. Expression pattern of circadian genes and steroidogenesis-related genes after testosterone stimulation in the human ovary. J Ovarian Res. 2016;9(1):1-7.

93.Lee B, Li A, Hansen KF, Cao R, Yoon JH, Obrietan K. CREB Influences Timing and Entrainment of the SCN Circadian Clock. J Biol Rhythms. 2010 Dec;25(6):410-20.

94.Ramos-Lopez O, Samblas M, Milagro Fl, RiezuBoj JI, Crujeiras AB, Martinez JA, et al. Circadian gene methylation profiles are associated with obesity, metabolic disturbances and carbohydrate intake. Chronobiol Int. 2018;00(00):1-13.

95.Fernandez R, Moore V, Van Ryswyk E, Varcoe T, Rodgers R, March W, et al. Sleep disturbances in women with polycystic ovary syndrome: prevalence, pathophysiology, impact and management strategies. Nat Sci Sleep. 2018; Volume 10:45-64.

96.Dunaif A, Wu X, Lee A, Diamanti-Kandarakis E. Defects in insulin receptor signaling in vivo in the polycystic ovary syndrome (PCOS). Am J Physiol Metab. 2001;281(2):E392-9.

97.Vollmers C, Schmitz RJ, Nathanson J, Yeo G, Ecker JR, Panda S. Circadian oscillations of protein-coding and regulatory RNAs in a highly dynamic mammalian liver epigenome. Cell Metab. 2012 Dec;16(6):833-45.

98. Etchegaray J-P, Lee C, Wade PA, Reppert SM. Rhythmic histone acetylation underlies transcription in the mammalian circadian clock. Nature. 2003 Jan;421(6919):177-82.

99.Fogg PCM, O’Neill JS, Dobrzycki T, Calvert S, Lord EC, Mclntosh RLL, et al. Class Ila histone deacetylases are conserved regulators of circadian function. J Biol Chem. 2014;289(49):34341-8.

100.Jung-Hynes B, Reiter RJ, Ahmad N. Sirtuins, Melatonin and Circadian Rhythms: Building a Bridge between Aging and Cancer. Vol. 48, Journal of pineal research. 2010. p. 9-19.

101.Asher G, Gatfield D, Stratmann M, Reinke H, Dibner C, Kreppel F, et al. SIRT1 regulates circadian clock gene expression through PER2 deacetylation. Cell. 2008 Jul;134(2):317-28.

102.Nakahata Y, Kaluzova M, Grimaldi B, Sahar S, Hirayama J, Chen D, et al. The NAD+-dependent deacetylase SIRT1 modulates CLOCK-mediated 
chromatin remodeling and circadian control. Cell. 2008 Jul;134(2):329-40.

103.Masri S. Sirtuin-Dependent Clock Control: New Advances in Metabolism, Aging and Cancer. Vol. 18, Current opinion in clinical nutrition and metabolic care. 2015. p. 521-7.

104.Schug TT, Li X. Sirtuin 1 in lipid metabolism and obesity. Ann Med. 2011;43(3):198-211.

105. Martins I, Wilson A, Lim WL, Laws S, Fuller S, Martins R. Sirtuin-1 mediates the obesity induced risk of common degenerative diseases: Alzheimer's disease, coronary artery disease and type 2 diabetes. 2012;

106.Yoshino J, Mills KF, Yoon MJ, Imai S. Nicotinamide mononucleotide, a key NAD+ intermediate, treats the pathophysiology of dietand age-induced diabetes in mice. Cell Metab. 2011; 14(4):528-36.

107.Kiyak Caglayan E, Engin-Ustun Y, Gocmen AY, Polat MF, Aktulay A. Serum sirtuin 1 levels in patients with polycystic ovary syndrome. J Obstet Gynaecol. 2015;35(6):608-11.

108.Ma X, Hayes E, Biswas A, Seger C, Prizant H, Hammes SR, et al. Androgens Regulate Ovarian Gene Expression Through Modulation of Ezh2 Expression and Activity. Vol. 158, Endocrinology. 2017. p. 2944-54.

109. Hansen KF, Sakamoto K, Obrietan K. MicroRNAs: A potential interface between the circadian clock and human health. Genome Med. 2011;3(2):1-8.

110.Cheng HYM, Papp JW, Varlamova O, Dziema H, Russell B, Curfman JP, et al. microRNA Modulation of Circadian-Clock Period and Entrainment. Neuron. 2007;54(5):813-29.

111.Cheng HYM, Obrietan K. Revealing a role of microRNAs in the regulation of the biological clock. Cell Cycle. 2007;6(24):3034-8.

112.Alvarez-Saavedra M, Antoun G, Yanagiya A, Oliva-Hernandez R, Cornejo-Palma D, PerezIratxeta $C$, et al. miRNA-132 orchestrates chromatin remodeling and translational control of the circadian clock. Hum Mol Genet. 2011;20(4):731-51.

113.Figueredo DDS, Barbosa MR, Gitaí DLG, De Andrade TG. Predicted microRNAs for mammalian circadian rhythms. J Biol Rhythms. 2013;28(2):107-16.

114.Crisponi L, Deiana M, Loi A, Chiappe F, Uda M, Amati $P$, et al. The putative forkhead transcription factor FOXL2 is mutated in blepharophimosis/ptosis/epicanthus inversus syndrome. Nat Genet. 2001;27(2):159.

115. Uhlenhaut NH, Jakob S, Anlag K, Eisenberger T, Sekido R, Kress J, et al. Somatic sex reprogramming of adult ovaries to testes by FOXL2 ablation. Cell. 2009;139(6):1130-42.

116.Kochan DZ, Ilnytskyy Y, Golubov A, Deibel SH, McDonald RJ, Kovalchuk O. Circadian disruption-induced microRNAome deregulation in rat mammary gland tissues. Oncoscience. 2015;2(4):428-42.

117.Long W, Zhao C, Ji C, Ding H, Cui Y, Guo X, et al. Characterization of Serum MicroRNAs Profile of PCOS and Identification of Novel Non-Invasive Biomarkers. Cell Physiol Biochem. 2014;33(5):1304-15.

118.Hong Z, Feng Z, Sai Z, Tao S. PER3, a novel target of miR-103, plays a suppressive role in colorectal cancer In vitro. BMB Rep. 2014;47(9):500-5.

119.Sørensen $A E$, Wissing $M L$, Englund $A L M$, Dalgaard LT. MicroRNA species in follicular fluid associating with polycystic ovary syndrome and related intermediary phenotypes. J Clin Endocrinol Metab. 2016;101(4):1579-89.

120.Yoo S-H, Kojima S, Shimomura K, Koike N, Buhr ED, Furukawa T, et al. Period2 3'-UTR and microRNA-24 regulate circadian rhythms by repressing PERIOD2 protein accumulation. Proc Natl Acad Sci. 2017;201706611.

121.Rongmin Chen, Matthew D'Alessandro and CL. miRNAs are required for generating a time-delay critical for the circadian oscillator. Curr Biol. 2014;23(20).

122.Sirotkin A V, Ovcharenko D, Grossmann R, Laukova $M$, Mlyncek M. Identification of microRNAs controlling human ovarian cell steroidogenesis via a genome-scale screen. J Cell Physiol. 2009 May;219(2):415-20.

123.Murri $M$, Insenser $M$, Fernandez-Duran $E$, SanMillan JL, Escobar-Morreale HF. Effects of polycystic ovary syndrome (PCOS), sex hormones, and obesity on circulating miRNA-21, 
miRNA-27b, miRNA-103, and miRNA-155 expression. J Clin Endocrinol Metab. 2013 Nov;98(11):E1835-44.

124.Wazen RM, Kuroda S, Nishio C, Sellin K, Brunski JB, Nanci A. Gene expression profiling and histomorphometric analyses of the early bone healing response around nanotextured implants. Nanomedicine. 2013;8(9):1385-95. 